\title{
Materials Education: Opportunities over a Lifetime
}

\section{A Report on the 17th Biennial Conference of the Federation of Materials Societies (FMS)}

Iver E. Anderson, Lyle H. Schwartz, Katherine T. Faber, G. Slade Cargill III, and Betsy Houston

\section{$\underline{\text { Introduction }}$}

Through the initiative of the current FMS President, Dr. Lyle Schwartz, the focus of the 2002 FMS Biennial Meeting was fixed on the topic of materials education, specifically to test this choice of direction for reinvigoration of FMS. As spelled out in the proposed (January 2001) FMS Business Plan; "Educational efforts of the individual societies will be enhanced by joint efforts facilitated under the umbrella of the FMS. Current focus will be on those activities aimed at increasing undergraduate enrollment in materials programs. ......FMS would play the role of host and facilitator for the members' joint efforts, and funding would come from society resources augmented by special fund-raising efforts from government and private sector sources." Further, the performance expectations for FMS were specified, as follows: "FMS will work with member societies to identify and pursue joint efforts in the educational arena at all academic levels that are targeted at increasing awareness about and enrollment in materials related fields at the collegiate level."

It was with that background that a small steering committee, including Iver E. Anderson, Slade Cargill, Kathy Faber, and Betsy Houston, began organizing this meeting. Although we started with the normal FMS Biennial organization model, the plans for this meeting quickly evolved to include both FMS and the University Materials Council (UMC) as a full partner in this enterprise, since its eventual outcome is critical to the future strength of both organizations. You will find a description of the exciting agenda of speakers (with abstracts) and events that comprised "Materials Education: Opportunities Over a Lifetime" along with this summary. We have also tried to provide a condensation of the purpose and scope of the meeting and an immediate summary of the conclusions and recommendations for action in the text that 
follows. When reviewing these materials, it is important to come to your own conclusions about how the action items (especially) can provide a high value for the member societies of FMS and how the entire Materials Science and Engineering field can benefit from the synergistic efforts that are proposed. Also, all readers are encouraged to supplement or refine the list of observations and recommendations that are provided, taking care to keep the best interests of the entire field in mind.

\section{Purpose: Materials Education: Opportunities Over a Lifetime was} designed for a thorough interchange of beneficial ideas and practices in materials science and engineering education among concerned citizens, professional educators, and funders/policy makers. As its title implies, the conference addressed the gamut of materials education issues at the grassroots, K-12, and college/university levels. Materials Education:

Opportunities over a Lifetime was a unique opportunity for the entire materials community to meet and exchange information, ideas, and plans.

Goals: All groups involved in materials education enterprise learned about the possibilities for parallel activities and collaboration. Professional educators and researchers became aware of the broad spectrum of potential sources of support. Funding organizations and policy makers became acquainted with the needs, opportunities and activities in materials education at all levels.

Highlights: The keynote address was delivered by Joanna Cole, author of the popular children's science book series, The Magic School Bus. A banquet address also was presented by Rep. Rush Holt (D-NJ), a prominent member of Congress who has been a leader in the public policy arena for science, math, engineering and technology education. Following the invited talks in each session, a roundtable discussion helped to involve all participants in the key discussion items that were raised. A poster session that operated on both days of the conference provided a chance for interested participants to display and describe exhibits from their own Materials Education projects. All inputs and recommendations were gathered into a summary and action plan (see below) which will be widely distributed to technical and professional societies, universities, K-12 educators and their organizations, and government policy makers.

\section{General Summary}


Lyle Schwartz, President, FMS

May 21, 2002

\section{General Observations}

* Exciting presentations, well organized sessions, enormous evidence of energetic involvement.

Lots going on, so what's the issue?

No measures of impact, little evidence of positive change on National level.*

*comment from Lance Davis-NAE, member of organizing committee

\section{FMS Education Role}

Concerns of Our Member Societies:

* Public Awareness: Stimulate more people to understand/appreciate Science and Engineering, public science literacy, create a technically informed democracy, promote National support for the research enterprise in the Physical Sciences and Engineering.

* Feed the Pipeline: Stimulate more science/engineering majors in colleges and universities.

Recruit from the Pipeline: Stimulate specific selection of Materials Science and Engineering options by students.

The Challenge 
* Each FMS member society has projects underway.

* Few are national in scope.

* We may be engaged in "feel good," but low payoff efforts.

* Can we find a few important areas and use FMS to make a difference?

\section{$\underline{\text { Issues }}$}

* Was "Pride of Ownership" syndrome keeping small projects separated?

No! Participants at this meeting suggest that is not an issue.

* Does a lack of resources hinder the efforts of individual projects?

Yes! Many (most?) of our member societies are lacking sufficient funds/volunteers to fully implement efforts.

* Focus should be directed to activities with National reach that can be supported locally by Chapters and Materials Clubs at Universities

\section{Basic Principles for Collaboration}

Selection of focus for collective action:

* Opportunity for National reach.

* Expand existing projects, don't create new ones, at this point.

* Several Member Societies should be involved. 
* The more inclusive the project, the better.

\section{$\underline{\text { Important Ideas }}$}

* Reach children early (start at grade 3-4) to influence entry into science.

Support curiosity of students to influence focus on Materials Science and Engineering (grade 7-12).

* Teacher training is at the heart of the problem. Addresses "feeding the pipeline" AND "recruiting from the pipeline".

Many opportunities abound in existing sub-national programs.

\section{Project Options for "Teach the Teachers"}

\section{Materials Camp}

Expand to new sites.

Participate in identifying applicants.

Focus on High School Teachers Camp?

Use EMTECH and/or MWM?

\section{Materials World Modules (MWM)}

Expand the market to include teacher training.

Identify corporate sponsors.

Educate the educators.

\section{Advanced Technology Center}

Join with ASM, SME.

Join MAGSTEM proposal.

Expand some already existing national program, e.g. NSTA competition. Include contributions from Materials Science and Engineering in PhysTEC. 


\section{MRS Traveling Museum Exhibit}

Raise funds for new sites.

Prepare visited cities for maximum participation using volunteers from local Chapters and Materials Clubs at Universities.

\section{Next Steps-Near Term}

* Form standing FMS Committee on Materials Education.

* Create a Clearing House for current activities (combining the efforts of others, e.g. MWM, NSTA, NEW)

* Continue the collaboration with UMC and develop linkage to NSTA.

* Use the MRSECs and other NSF-funded programs for National leverage.

* Confirm selection of the initial project(s), working with the Lead Societies, set an agenda for collaboration, and DO IT!

* Explore advocacy role for FMS in support of funding for Dept. of Education role in Math and Science Partnerships (possible major support).

\section{Next Steps-Long Term}

* Develop a long-term roadmap with Member Societies describing goals of the program including vision, targeted milestones, and metrics.

* Formalize cooperation through strategic alliances. 


\section{$\underline{\text { Summary }}$}

* FMS can play a role of coordination and facilitation in the educational arena

* We will focus our energies on "Teach the Teacher" for maximum impact.

* Stay tuned! 


\title{
APPENDIX:
}

\section{Conclusions and Recommendations from each Session Chair:}

\author{
Session I: Grassroots \\ Iver E. Anderson \\ May 21, 2002
}

\section{Motivations for Enhancement of Materials Education:}

* Recharge the pipeline of materials scientists and engineers to replenish the aging workforce in many areas of manufacturing, academia, and government laboratories. Reverse the trend of declining memberships in technical societies related to materials science and engineering.

* Influence policy makers to provide additional funding for education and research in the materials science field.

* Raise the overall level of materials science literacy in the population to enable the functioning of a more interactive and informed democracy.

\section{Recommended Mechanisms to Reach the General Public:}

* Materials Science should be FUN! FMS should encourage the development of new museum and science center displays.

Science displays must be enjoyable and accurate.

Learn and refine exhibits from public feedback.

Local chapters of materials societies could promote and staff traveling exhibits.

* FMS could facilitate the assembly of a catalogue of the diverse collection of existing Materials Science displays and demonstrations that have been developed.

A Magic School Bus book should be commissioned by FMS from Scholastic Books to permit Joanna Cole to develop a Materials Science title with broad impact for elementary readers. 
* A National Materials Week could be created to raise public awareness of our profession, where FMS could coordinate national outreach activities.

\section{General Enabling Activities:}

* Considerable effort is needed to condense each scientific message to an attractive form that can be widely understood and all materials scientist should practice this skill.

Retain scientific accuracy, while avoiding jargon.

Illustrate the scientific method by a storytelling style, e.g. mystery.

Describe the failures and successes to illustrate the scientific process.

* Media outreach should be encouraged among materials scientists to engage the public in thinking about the benefits, challenges, and triumphs of materials science.

Target media with broad reach, e.g., television, radio, Internet.

* Public forums should be sought for local science demonstrations with trained volunteers to increase the learning impact.

Build from the materials developed for museums and classrooms.

Reach the people at malls, fairs, and school events.

\section{Other Program Proposals:}

* A "Family Materials Science" program could be created to involve families who want their children to learn about the world of science and to share more quality time.

Develop curriculum with funding from, e.g., NSF.

Science museums and universities should host on weekends.

Train young "Peer Teachers" to provide a bridge to the schools.

* A set of Materials Science activities could be developed for the ZOOM show on PBS and grouped under the rubric "ZOOM into Materials Science."

Combined funding from FMS member societies to develop.

Society members would be trained as activity leaders.

\section{Session II: K-12 Education}

\section{Kathy Faber}


May 21, 2002.

\section{Conclusions and Recommendations:}

* Materials societies should work in conjunction with NSTA to identify opportunities for the materials communities to bring materials science and engineering to teachers of science.

The expansion of "Teacher in Residence" or Teacher Camp Programs should be lobbied for by FMS and supported by federal funds.

* Expand Materials Camps to more venues. FMS help?

* Materials societies and universities should enlist the support of industry to recruit students to the MSE discipline. Industrial programs should be brought to lower levels, i.e. middle schools.

Determine the limiting factor in distribution/implementation of MWM; FMS role?

FMS working with ASM should catalog the myriad of K-12 MSE educational activities to identify redundancy, best practices, and holes.

\section{Session III: College, University, and Continuing Education}

\section{Slade Cargill}

May 24, 2002

\section{Conclusions:}

* Materials courses for non-science/engineering students can introduce science concepts and reasoning to students who might otherwise graduate with no exposure to physical sciences.

* Materials science and engineering programs face challenges in growing and maintaining undergraduate enrollments commensurate with opportunities for BS, MS and Ph.D. employment. 
* "Common freshman year" curricula and contacts with freshman-year students, e.g. through materials chemistry, engineering projects, or introduction to engineering courses, are important for recruiting students to materials programs.

\section{$\underline{\text { Recommendations: }}$}

* More college-level exposure to materials science should be provided for both science and engineering majors and non-majors, because materials science underlies past, current and future technologies.

* Materials education should reflect the interdisciplinary nature of current advances in materials research and applications.

* Materials societies should collaborate with one another and with college/university materials departments in marketing materials education and career opportunities.

* Materials departments should play more active roles in training teachers of science and engineering for primary and secondary schools.

\section{CONFERENCE ABSTRACTS}

\section{PLENARY LECTURE}

The Magic School Bus Drives into Materials Science Joanna Cole, Author

It was the end of a typical American school day. Our class had studied reading, math, computer skills, traffic safety, fire safety, stairwell safety, and the history of our city, county, and state. We had charted our family trees, read aloud from Harry Potter, made a "creative" map of Bermuda using only macaroni and string, and listened to a local police officer speak on the subject of avoiding date rape. Now we kids had only one question: When are we going to find time to learn about MATERIALS SCIENCE??!

Joanna Cole loved science as a child. "I always enjoyed explaining things and writing reports for class. I had a teacher who was a little like Ms. Frizzle. She loved her subject. Every week she had a child do an experiment in front 
of the room and I wanted to be that child every week," she recalls. It's no surprise that her favorite book as a child was Bugs, Insects and Such.

Ms. Cole has worked as an elementary school teacher, a librarian, and a children's book editor. Combining her knowledge of children's literature with her love of science, she decided to write children's books. Her first book was Cockroaches, which she wrote because there had never been a book written about the insect before, and "I had ample time to study that creature in my low-budget New York apartment!" Since then she has written more than 50 nonfiction and fiction books for children, and she is the winner of the 1991 Washington Post/Children's Book Guild Non-fiction award for the body of her work, which also includes the ALA Notable Children's Book How You Were Born; Bony Legs; Cars and How They Go and, with Stephanie Calmenson, Give a Dog a Bone.

Despite the hard work, Ms. Cole insists that writing is the greatest fun in the world. And the Magic School Bus books in particular provide the opportunity for Ms. Cole to combine the two things she loves: science and humor.

\section{PRESENTATIONS}

\section{Communicating Science to the People}

Robert Coontz, Editor, Science Magazine

Only a minuscule fraction of scientific research ever makes it into the popular media. To scientists, the winnowing process by which editors decide which science stories get told can seem bewildering and arbitrary, but it is logical (if sometimes messy). To understand how journalists communicate science, researchers must realize "what the public 'should' know" is only part of the newsmaking algorithm. Deadlines, space pressures, concepts of timeliness and story, and judgments about what people "want" to know (or will sit still for) also play major roles in shaping coverage.

\section{The Role of Science Centers: Developing Science Itself with the Help of "Ordinary People" \\ Hooley McLaughlin, Senior Advisor, Ontario Science Centre}

The Materials Research Society is developing a traveling public exhibition on materials science, with the aid of a team that includes materials scientists, museum 
advisers, public education evaluators, and research, design, and fabrication staff at the Ontario Science Centre in Toronto. This presentation will engage participants in a discussion on the role the interactive science center exhibition plays in the development of public literacy in science. The MRS exhibition has an ambitious mandate in that it endeavors to engender a basic understanding of the essential parameters of materials sciences - structure (both the underlying micro and the more overt macro aspects), properties, performance, and processing. As daunting a task as this is, a science center exhibition effectively goes further. It becomes a meetingpoint for active scientific researchers and the average intelligent member of the public. Through the process of developing a public exhibition, the MRS is examining the basic nature of the materials sciences themselves. The goal of this session, therefore, will be to examine the premise that public education is not unidirectional.The future trajectory of a science is affected by the creation of a public education interface. The MRS exhibition could very well result in self-reflection within the Society and in new thinking with regard to the science of materials in the future.

\section{Why Should I Listen? The Importance of Bears, Onions, and Harry in Explaining Science \\ David Kestenbaum, Correspondent, National Public Radio}

After college, learning is optional. This seems particularly true when the subject is science. In one study NPR has done, the average person was more interested in stock prices than a story about the origin of the universe. One obvious solution is to mention stock prices while you are talking about science. Even better is to hide the science in a story that seems to be about something else. A real story, with characters, maybe even a bear or an onion.

\section{Bringing the Excitement of Physics to the Public on PhysicsCentral.com, or Fighting the War on Error Jessica Clark, Public Outreach Specialist, American Physical Society}

Launched in December 2000, PhysicsCentral.com is a major public outreach initiative of the American Physical Society. A web site in a magazine-like format with continually updated content, it is designed to bring the excitement and importance of physics to everyone in a simplified but not simplistic way. It features both pedagogical elements and descriptions of recent developments in fast-moving areas of current research. PhysicsCentral is designed to be attractive and informative, and to emphasize that physics is an interesting pursuit carried out by interesting people. Visitors to the site can learn a little bit of physics, can find out what is happening on the research frontier, and can find links to the rest of the best physics sites on the web. Physics Central carries the imprimatur of the American Physical 
Society and plays a unique role that is not duplicated by any other site in the universe.

\section{Collaborating with "The Enemy": Using the TV for Materials Education Alexis Clare, Professor, Alfred University}

A speaker at our opening Convocation quoted the following phrase: "TV is called a 'medium' because it is neither rare nor well-done." People in education have often taken a dim view of television as a competitor for the interests and time of their scholars but used in the right way television is a tremendous educational tool, not only in the classroom but in public awareness and recruiting to the field. This talk will discuss our experiences using TV for class education, public education and recruiting students for Materials Science and Engineering. The future prospects incorporating new technology and some new ideas will also be discussed.

\section{Engaging K-12 Children in Physical Science Competitions: Success Stories and Classroom Interactions}

Gerry Wheeler, Executive Director, National Science Teachers Association

Over the past two decades the National Science Teachers Association (NSTA) has conducted a number of student competitions involving over a quarter of a million students and tens of thousands of teachers. The sponsors included corporations and governmental agencies. This talk will highlight the success and failures of these experiences as well as the benefits to the participants.

\section{The Blame Game in the Science Preparation of Future Teachers} Fredrick M. Stein, Director of Education and Outreach, American Physical Society

Who is responsible for the general lack of science preparation in our newly-certified $\mathrm{K}-12$ teachers? If it is true that teachers "teach as they were taught," then we must look to the college and university departments. The American Physical Society (APS), in partnership with the American Association of Physics Teachers (AAPT) and the American Institute of Physics (AIP), has initiated PhysTEC in concert with national reports calling for the improvement of K-12 science teaching. PhysTEC aims to help physics and education faculty work together to provide an education for future teachers that emphasizes a student-centered, hands-on, inquiry-based approach to learning science. Program components include: (1) A long-term, active collaboration between the physics department, the education department, and the local school community; (2) A Teacher-in-Residence (TIR) program that provides for a local K-12 science teacher to become a full-time participant in assisting faculty with both team-teaching and course revisions; (3) The redesign of content and pedagogy of targeted physics courses based on results from physics education 
research as well as utilization of appropriate interactive technologies; (4) The redesign of content and pedagogy for elementary and secondary science methods courses with an emphasis on inquiry-based, hands-on, approaches to teaching and learning; and (5) The establishment of a mentoring program for TIRs and other Master Teachers designed to meet the needs of an induction experience for novice science teachers. This includes the participation of physics faculty in increasing and improving a wide array of school experiences.

\section{Materials Camp: High School Students Learn that Careers in Materials and Engineering can be a Lot of Fun \\ Charles R. Hayes, Executive Director, ASM International Foundation; and Thomas Stoebe, Professor Emeritus, University of Washington}

MATERIALS CAMP is a one-week live-in summer experience in materials science and engineering for high school juniors. The program, sponsored by the ASM Foundation, provides 60 students with real-life, hands-on experiences in materials science and technology. Students are recruited globally for MATERIALS CAMP programs currently located at two sites, ASM Headquarters near Cleveland, $\mathrm{OH}$, and University of Washington in Seattle, WA.

The MATERIALS CAMP program is divided into three segments, one dealing with materials background knowledge, the second relating to a materials failure project and the third relating to career awareness, networking and related activities. Background knowledge is developed using parts of the Materials Science and Technology curriculum project, a program focused on high school level materials technology. Volunteer professionals (from ASM chapters and affiliates) act as mentors to the students as they carry out their failure analysis projects in teams, learning to use basic metallographic and analytical equipment. Career awareness comes from interacting with the professionals present, field trips and social activities.

\section{The Development of a Dynamic Materials Educational Program for Pre-College Students R.P.H. Chang, Professor, Northwestern University}

The Materials World Modules Program is designed to use inquiry-based activities and design projects on materials topics for middle and high school students. Each module has a teacher's booklet, a student's booklet, and a materials kit for the whole class. These modules are used to connect science concepts to the world we live in through the use of materials. Today, nine modules are in circulation and a tenth module is under development. In addition, an internet version of the modules is under development and is also being field-tested. In this talk, I will discuss the dynamics of the program and the potential impact to science and math education. 


\section{An Innovative University-Industry Initiative to Enhance and Improve Enrollment of K-12 Students into Science and Engineering Programs Ranji Vaidyanathan, Manager of Advanced Materials, Advanced Ceramics Research, Inc.}

The Summer Engineering Academy (SEA) is an innovative partnership between the University of Arizona and local businesses to attract qualified high school students into engineering disciplines. The idea is to show students how an idea becomes reality. Students learn to use sophisticated 3-D modeling and design software to design aerodynamic cars and produce models using Rapid Prototyping techniques. They attend lectures conducted by university faculty and industry personnel. The students' designs are emailed to Advanced Ceramics Research and the parts are built for the teams on the rapid prototyping machine while the students are touring the facilities. The participants test their model cars in a specially built wind tunnel and make a PowerPoint presentation to an audience of about 300 on the last day of the week-long program. For a total of 80 seats, nearly 500 students from all over the U.S. apply. Out of the students who attended in 1999, 27 students have enrolled in the University of Arizona engineering programs, with similar results for the 2001 program. There has been a clear improvement in the number of minority and women students entering the undergraduate engineering program after the Summer Engineering Academy was initiated. It is expected that participation in this program would encourage students to enter into engineering programs, become interested in graduate school and employment in industries of the future with rapid prototyping and flexible manufacturing industries.

\section{Diversity in Materials Research and Education: An NSF Perspective Lance Haworth, Executive Officer, Division of Materials Research, National Science Foundation}

Despite some gains over the past decade, the representation of women and minorities among NSF grantees in materials research - a field ranging broadly from fundamental condensed matter physics and solid state chemistry to functional materials including polymers, ceramics, metals and electronic and optical materials is still much lower than their representation in the US population as a whole. The 'leaky pipeline' for science starts in elementary school and secondary school and progresses through undergraduate, graduate and postdoctoral programs to the faculty level. Science in general, and materials science in particular, underlie current and future technologies and will have a profound impact on life in the 21 st century. Yet public awareness of and appreciation for the value and importance of materials research remains low, and its potential as a vehicle for science education remains largely untapped. The challenges of science education, diversity in science, and public awareness of science are strongly related. What is being done, and what might be done better, to address these challenges for materials science in particular? In this brief talk I will try to give an NSF perspective on these issues and some thoughts on possible future directions. 


\section{Materials Education in the New Century \\ Subra Suresh, Professor, Massachusetts Institute of Technology}

This presentation will provide some views on how the curricula and the character of Materials Science and Engineering departments are likely to evolve in the coming years in light of technological, industrial, academic and social trends. Particular attention will also be devoted to an examination of how rapidly evolving distanceeducation and communication technologies will influence teaching and research in these departments. Evolving trends in the broadening of coverage in materials education from the classical processing-structure-properties-performance connections in materials to include such hitherto disconnected topics as biology, information technology and systems engineering for materials used in small-volume applications will also be considered.

\section{Materials and their Role in Shaping our World From the Stone Age to the Age of Silicon: Making Science Accessible to Non-Scientists Stephen L. Sass, Professor, Cornell University}

Materials have enabled revolutionary advances in how we work, fight, live and travel, hence the naming of eras after them - the Stone, Bronze and Iron Ages. My book, The Substance of Civilization: Materials and Human History from the Stone Age to the Age of Silicon, and the course based on it, explores the role of materials in the development of modern industrial Western civilization by embedding technology in a historical context. My course, which is designed to satisfy the science requirement for non-scientists in the Arts College at Cornell, traces the advances made possible by innovations with stone, ceramics, glass, metals and electronic materials, starting with the Stone Age. Connections between critical developments are identified and explored, for example, the relationships among materials, agriculture and written languages in the fourth millennium B.C., and among the Exodus of the Hebrews, the general tumult in the Eastern Mediterranean and the onset of the Iron Age, at the end of the second millennium B.C. The roles of China and Islam in stimulating revolutionary advances in technology are examined. Beautiful works of art illustrate early technologies. Lectures, demonstrations and hands-on laboratory experiments elucidate the origin of the unique properties of materials such as polymers, ceramics, metals and glass.

William D. Callister, Adjunct Professor, University of Utah

This presentation will discuss a number of issues that pertain to the introductory materials science and engineering course taught at the college/university level. Topics to be addressed include the following: (1) the "typical" introductory course; (2) generating student interest; (3) providing relevance to topic discussion; (4) dealing with the breadth versus width dilemma; (5) traditional (i.e., "metals first") versus integrated organizational approaches; (6) topic coverage decisions; (7) incorporation of a design component; (8) computer/web resources (visualization 
software packages, web-based testing/homework/self-assessment schemes, web sites, instructor ancillary materials, electronic texts); and (9) textbook issues.

\section{Demonstrations for Materials Education: Making the Nanoworld Comprehensible \\ Arthur B. Ellis, Professor, University of Wisconsin-Madison}

Nanotechnology is a frontier of materials science that can capture the imagination of teachers, students, and non-technical audiences. A challenge in communicating themes from nanoscale science and engineering is to make the tools, materials and devices associated with nanotechnology accessible. This presentation will include a number of hands-on demonstrations that show how materials can be imaged and constructed on the nanoscale; and how their electrical, magnetic, mechanical and optical properties can be manipulated to create new materials and devices.

\section{Continuing Education, Lifelong Learning and the Materials Profession Frank Mayadas, Program Director, Alfred B. Sloan Foundation}

Materials Science, along with associated design and manufacturing tools and techniques, is at the heart of the revolution that has enabled production of smaller, lighter, cheaper and more reliable products in manufacturing industries. This is true for consumer or industrial products, which are also being introduced into the marketplace at a quickening pace. These trends will continue, and they will force an even closer relationship between industry and academe, as engineers and scientists strive to stay abreast of new developments in the materials fields. This against a backdrop in which societal trends are reducing the discretionary time available for study, course-taking etc. Internet learning provides a partial solution. In this talk, we will discuss what is actually being done today in the use of computers and the internet for technical education and training, and what is likely to happen in the coming years, and why this is important for continuing the kind of progress we have recently seen.

\section{THE CONGRESSIONAL PERSPECTIVE}

The Honorable Rush Holt, U.S. House of Representatives

Rush Holt has represented the 12th Congressional District of New Jersey in the U.S. House of Representatives since 1999. Born in West Virginia, he inherited his interest in politics from his parents. His father was the youngest person ever to be elected to the U.S. Senate, at age 29, and his mother was the only woman ever to serve as Secretary of State of West Virginia. 
Rep. Holt entered politics after a distinguished career as a physicist. From 1989 until he began his 1998 Congressional campaign, Rep. Holt was Assistant Director of the Princeton Plasma Physics Laboratory, the largest research facility of Princeton University and the largest center for research in alternative energy in New Jersey.

After receiving his B.A. in Physics from Carleton College in Minnesota and his Masters and Ph.D. from NYU, Rep. Holt served as a physics professor at Swarthmore College, a Congressional Science Fellow in the office of thenRep. Bob Edgar (1982-83), and Acting Chief, Nuclear and Scientific Division, Office of Strategic Forces Analysis, U.S. State Department, before assuming his duties at Princeton.

Recognizing Rep. Holt's standing among his colleagues, he has been appointed to the leadership in Congress as an At-Large Democratic Whip .and is a member of the New Democrat Coalition.

Rep. Holt is a tireless advocate for science, engineering and technology funding in Congress. From his positions on the House Budget Committee and the House Committee on Education and the Workforce, he has been instrumental in promoting increased federal investment in research and development, and in supporting math, science and engineering education programs. His work in support of the 21st Century Science Teachers Skills Project has been especially crucial the last two years. From his own experience, Rep. Holt is an outspoken advocate of the Congressional Fellows program, and is currently spearheading an effort to revive the Congressional Office of Technology Assessment to provide members of the House and Senate their own resource for independent analysis of the increasingly complex technical issues of the 21 st century.

In addition to all his other accomplishments, Rep. Holt is a five-time winner of the game show "Jeopardy".

\section{POSTER SESSION/DISPLAYS}

\section{Materials Societies displays:}

The American Ceramic Society, Inc.

ASM International

Materials Research Society

The Minerals, Metals and Materials Society 


\section{Enhancement of Materials Science for Manufacturing Program John M. Rusin, Edmonds Community College; and Thomas G. Stoebe, University of Washington}

Materials Technology and Science are topics that excite students' interest because the student has everyday, hands-on experience with materials. Thus materials topics are great motivators in any engineering, technology or science course. Materials Science activities can also be used in both academic and vocational courses and thus assist in the transition for technology students across the high school-community college boundary Edmonds Community College in Lynnwood, WA, has been awarded a three-year, \$1.05 million grant from the National Science Foundation to conduct teacher training in materials science and to establish a materials science resource center for teachers and students.

\section{Outreach and Educational Activities from the University of Kentucky Janet Lumpp, University of Kentucky}

UK's outreach activities include work with elementary and high-school students and teachers. Teacher workshops on electronics are part of KEEP (Kentucky Electronics Education Project) training math and science teachers grades 5-12 in basic circuit fabrication skills. KEEP uses microelectronics as a theme for math and science topics with lesson plans and activities consistent with the Core Content for Assessment and the National Science and Education Standards.

\section{Creating Opportunities for Women in Materials Research Velda Goldberg, Simmons College}

This three-year collaboration between a predominantly undergraduate women's college (Simmons College) and a NSF-supported MRSEC (the Cornell Center for Materials Research (CCMR)) focuses on establishing a collaborative Simmons/Cornell research program that provides opportunities for students to work with faculty on timely research projects, have access to sophisticated instrumentation, and gain related work experience in industrial settings. The project also uses the PUI/MRSEC collaboration to enhance the undergraduate curriculum and encourage new Ph.D.s in materials-related disciplines to consider academic careers at PUIs.

\section{Reaching Elementary School Children: Face to Face with S\&T Kits Velda Goldberg, Simmons College}

Face to Face with Science and Technology Kits stress aspects of science and technology found in the everyday world. Kits such as Treating Vascular Disease, Inventing the Pen, or Designing Automobile Brakes illustrate real-world products or processes and help children to view science and technology in the context of their 
everyday lives. These materials grew out of the NSF-sponsored project, "IndustrySchool Collaboration: Products, Processes and Technology in the Elementary School Curriculum."

\section{Center for the Science and Engineering of Materials: Education and Outreach Bob de Groot, Caltech}

The outreach efforts of the Caltech Center for the Science and Engineering of Materials (CSEM), an NSF-supported MRSEC, are: (1) the Materials Partnership with California State University at Los Angeles $(82 \%$ are from underrepresented groups) which includes faculty interactions, collaborative research projects and enhancing experimental facilities; (2) Development of high school science materials and experiences designed to involve Native American students in technical fields; (3) Development of middle-school hands-on science instructional materials; (4) Development and production for public television of a 10-episode educational video series and Web-based curriculum on the role of materials in our lives.

\section{Baby Steps: A Materials Outreach Program to the K-12 Community Kelly P. Eaton, Lehigh University}

An intensive effort at Lehigh University to develop a close relationship with surrounding K-12 schools has been initiated in the Education College in conjunction with the Institute for Metal Forming and the Materials Science Department . As a result of this work a Website "Ask the Engineer" has been constructed for middle school students. Additionally a Website promoting materials science and engineering through information, experiments, and lesson plans was prepared for high school students and teachers. Several interactive classroom presentations have already been made by a graduate student, and a network consisting of about a dozen schools has been created. Future plans include developing collaborative programs and assuring their presence in local schools

\section{MicroWorlds: Exploring the Structure of Materials Elizabeth Moxon, Lawrence Berkeley National Laboratory}

MicroWorlds is an electronic science magazine on the Web. Written for students in grades 7-12, their teachers, and the general public, it features information about research at the Advanced Light Source, a third-generation synchroton at LBNL. MicroWorlds has several unique features that sets it apart from many Web educational projects: it features real science, and the scientists, engineers and support staff that make outstanding research happen; it connects key science concepts like electromagnetism and light to the way the concepts are used in everyday life, 
engineering, and science; the material is integrated with hands-on activities that make the student a participant in the learning process; and it is developed by ALS writers in collaboration with teachers and students. Three teaching modules guide students on a path of scientific discovery as they unravel clues that lead them on an exploration of the world of materials science.

\section{High School Student and Teacher Programs at Penn}

Andrew R. McGhie, University of Pennsylvania

The NSF-supported MRSEC at the University of Pennsylvania undertakes a variety of educational outreach programs to all sectors of the community. In this poster we describe five such programs for schools: (1) A Research Experience for Teachers program which brings five high school teachers into the materials lab for six weeks to work with a faculty member; (2) A REU program which brings 25 college juniors into our lab every summer; (3) A four week lecture/lab course for high school juniors in July; (4) A monthly lecture series for teachers; and (5) Lectures to schools via videoconferencing and cable television.

\section{PCCM's Science Curriculum Support and Teacher Training Project}

Daniel Steinberg, Princeton University

We have established a program to support hands-on inquiry based science curricula. Teams of teachers and PCCM faculty worked together on six different science kits from Foss and STC. A web site with science content help for teachers using these kits is maintained. Building on this experience, PCCM faculty have developed a unique electricity and magnetism kit for districts that have not yet adopted the commercialized kits. Four faculty conducted an all day training session recently for local lead teachers. Each lead teacher received training in our kits and was provided a kit to bring back to their schools.

\section{Materials Molding Civilization}

David Richerson, University of Utah

This class stimulates a greater interest and literacy in science for university students who normally would not have any exposure to science by presenting science through materials and history. The poster will address the content of the course and how other educators might adapt the concept to their own needs, and will address the challenges of getting students to sign up for a class listed under Materials Science and Engineering. 


\section{National Educators' Workshop - NEW:Updates \\ Jim Jacobs, Norfolk State University}

As a report of the Organizing Committee for NEW:Update 2002 to be hosted in Silicon Valley, October 13-17, 2002, this poster and display will provide information and useful resources from 17 years of past NEW:Updates including a CD-ROM, "Experiments in Materials Science, Engineering and Technology."

\section{Solid State Physics and Materials Science at Augsburg College} J. Ambrose Wolf, Augsburg College

In Fall 2001, Augsburg College approved a new concentration in Solid State Physics. In addition there is also the possibility for students to get hands-on experimental research experience in Augsburg's Solid State Physics Research Laboratory. There also are plans to introduce a bachelor's degree in Materials Science. The new programs go hand-in-hand with interest from both the industrial and the academic side.

\section{Materials Science and Engineering at the University of Maryland Isabel Lloyd and Kathleen Hart, University of Maryland}

We will feature information both from the Department and our ASM/TMS and ACerS student branch. The student display will emphasize professional development activities (local society meetings, annual meetings, guest speaker service (outreach and service to the department and university). The Department display will feature outreach materials and activities and our undergraduate laboratory activities including both our laboratory sequence and instudiosla in other classes. It will also highlight the variety of undergraduate research activities and options.

\section{Teaching Undergraduates Results from Recent Research as Part of a Lab} Luz J. Martinez-Miranda, University of Maryland

We have integrated recent results in research in the curriculum of the University of Maryland, while leaving the basics untouched. This allows us to teach the fundamental laws and to show the students how these help us to answer questions that are of importance today. This can be done as part of a laboratory class and as part of a class. In the laboratory classes, we emphasize what is measured (the main topic), then measure samples recently in the literature. These are then related to the manner the samples have been grown, and how they have been processed. Occasionally, we give students a five-point question that aims at relating their results and methodology with a recent problem in the literature. 


\section{The University of Maryland's MRSEC's Education Outreach Jennifer Stott, University of Maryland}

The Maryland MRSEC is committed to introducing, stimulating interest in, and teaching materials science to students and the community in an effort to inspire appreciation for science and to help shape the talent pool for the high tech workforce. Of equal importance, the Center's education outreach activities address national concerns about science learning. Current outreach activities include the Maryland MRSEC Research Experience for Undergraduates; coordination with local homeschooling groups to provide labs, lectures, and science fairs; development and implementation of materials science activities including lab tours, demonstrations and hands-on labs at pre-college institutions; coordination with the MRSEC K-12 Fellowship Program; participation in community events such as Physics Day at 6Flags Amusement Park and Maryland Day; and augmentation of existing Maryland programs including Physics is Phun Program and the Department of Physics Summer Girls' Program.

\section{CONFERENCE SPONSORS}

The Federation of Materials Societies (FMS) is an umbrella organization whose members represent the professional societies, universities and National Research Council organizations which are involved with materials science, engineering, and technology. FMS constituent societies have nearly one million members. FMS serves as a clearinghouse where materials professionals can share best practices, current activities, and the opportunities and problems cutting across specific materials concerns and materials societies. Through meetings and its Biennial Conferences on National Materials Policy - of which "Materials Education: Opportunities Over a Lifetimel"'is the 17th-FMS provides a forum where policy makers and the materials community meet to discuss issues, develop policy and recommend actions.

The University Materials Council (UMC) is composed of Department Heads, Chairpersons, Directors and group leaders from academic programs in the materials field in U.S. and Canadian universities. It serves as a forum to share best practices in areas such as student recruitment, and discuss issues such as emerging research areas, ideas for curricular improvements, ABET accreditation, patent right policies in universities, implications of the latest material related studies, and the health of research funding for Materials Science and Engineering. 